\title{
CHALLENGES AND LESSONS LEARNED FROM COASTAL FLOOD RESILIENCE PLANNING IN VIRGINIA BEACH, VIRGINIA, USA.
}

\author{
Brian K. Batten, Dewberry, bbatten@dewberry.com \\ Gregory Johnson, City of Virginia Beach, giohnson@vbgov.com \\ Shanda Davenport, City of Virginia Beach, sdavenpo@vbgov.com
}

\begin{abstract}
INTRODUCTION
Many U.S. coastal cities face the challenge of increasing flood frequency and magnitude due to a combination of increasing sea levels, changing rainfall, and aging infrastructure. Recurrent flooding, sometimes referred to as "nuisance flooding", can be symptomatic of such issues. Responding to such impacts can either be tacked in a piece-meal, reactive fashion, or proactively. A number of cities, such as New York (SIRR, 2013) and Boston (City of Boston, 2016) have undertaken or are in the process of planning efforts to recognize such issues and develop strategies to reduce impacts. The flood resilient planning process can take many forms, we shall provide a case-study example overview of a bottom-up, risk-informed effort by the City of Virginia Beach, VA.
\end{abstract}

\section{BACKGROUND}

Rising sea levels are a fact accepted by the City of Virginia Beach. As a thriving coastal city, it is fully committed to taking the needed actions to identify and implement measures that assure a vibrant future. The city is situated in the Hampton Roads region on the eastern Atlantic U.S. seaboard. The region is subject to the highest rate of historical sea level rise on the east coast (about $1.5 \mathrm{ft}$. in the last 100 years) due to relatively high rates of subsidence. SLR projections estimate that local water levels may increase by another 1 to $3 \mathrm{ft}$ over the next 30 years (Sweet et al. 2017).

\section{APPROACH AND RESULTS}

Virginia Beach executed a phased study effort to holistically assess existing and future flood risk, develop and evaluation resilience strategies, and then operationalize such strategies. The study Impact Assessment Phase measured the vulnerability, exposure, and economic flood risk of assets and critical infrastructure for existing conditions and two future SLR scenarios. A range of conditions including tidal, nuisance and storm surge driven coastal floods including combined probable stormwater runoff were evaluated. Results were conflated to a range of geographic units, including the City's major and minor watersheds, as well as strategic growth areas to align outputs with planning and engineering practices. Additional analyses were conducted to better inform infrastructure design, such as the joint probability of tidal elevations and rainfall, rainfall non-stationarity and future projections. Geospatial aggregation of the distribution and concentration of flood loss helped identify six focus areas for development of flood risk management strategies.
The Adaptation Strategy Phase of the study leveraged the Impact Assessment to develop risk-informed planning, policy, and engineered flood risk reduction strategies to decrease short- and long-term risk. Proposed policy, planning land use and ordinance strategies, were evaluated through work groups and a multi-factor feasibility rating framework to cull intractable items. Engineered solutions, including flood gates and perimeter protection, down to structure level strategies were evaluated in tandem with preferred policy through benefit cost analysis, internal work group discussions, and public feedback to help identify the most effective and acceptable hybrid solutions.

The final study phase will develop the watershed-level plans to provide conceptual design, overall costs, shortand long-term sequencing of strategy implementation, funding evaluation as well as and outreach activities in an actionable framework.

\section{SUMMARY}

Our presentation will provide an overview of the study effort, with highlights on lessons-learned from study methodologies and usefulness of results. Additionally, we will provide context on how study products were received by the community and early insights into operationalization of study recommendations. Supporting analysis and approaches to implement changes to city design standards to accommodate future sea level, non-stationary precipitation, and combined flood conditions will be discussed.

\section{ACKNOWLEDGMENTS}

Aspects of this effort were funded by National Oceanic and Atmospheric Administration Office of Coastal Management award number NA16NOS4730011.

\section{REFERENCES}

City of Boston (2016): Climate Ready Boston, Final Report, 199 pp.

Special Initiative for Rebuilding and Resiliency (2013): A Stronger More Resilient New York, New York City.

Sweet, et al. (2017): Global and Regional Sea Level Rise Scenarios for the United States. National Oceanic and Atmospheric Administration, 75 pp. 